\section{Please Join Us for AAAI / IAAI 2013 in Bellevue, Washington!}

The Twenty-Seventh AAAI Conference on Artificial Intelligence (AAAI-13) will be held July 14-18, 2013, at the Hyatt Regency in Bellevue, Washington, USA. The Twenty-Fifth Conference on Innovative Applications of Artificial Intelligence (IAAI-13) will be collocated with AAAI-13, and will be held July 16-18 (see www.aaai.org/ iaai13).

The AAAI program cochairs for 2013, Marie desJardins (University of Maryland, Baltimore County, USA) and Michael Littman (Brown University, USA) will continue the innovations introduced during the past several years of the conference, including the four special technical tracks and the AI Subarea Spotlight track. An overview of the special tracks is included below. For the full technical Call for Participation, as well as all program dead-

\section{AAAI / IAAI / EAAI 2013 Deadlines}

A few important deadlines to note on your calendar:

- January 17: IAAI-13 Papers due

- January 19: AAAI-13 Technical and Special Track Abstracts due

- January 22: AAAI-13 Technical and Special Track Papers due

- January 31: AAAI-13 Student Abstracts due

- February 5: AAAI-13 Doctoral Consortium Applications due

- February 6: EAAI-13 Papers due

- March 28: AAAI-13 Workshop submissions due

- April 9: All AAAI-13, IAAI13, and EAAI-13 cameraready papers due

- April 30: AAAI-13 Video Competition submissions due

\title{
AAAI News
}

\author{
Winter News from the \\ Association for the Advancement \\ of Artificial Intelligence
}

lines and guidelines, please visit the AAAI-13 website at www.aaai.org/ aaai13.

AAAI-13 will also include all of these ongoing programs!

- AAAI-13 Tutorial Forum

- AAAI-13 Workshop Program

- AAAI-13 Student Abstract and Poster Program

a Eighteenth AAAI/SIGART Doctoral Consortium

- AAAI Robotics Program

- AAAI General Game Playing Competition

- AAAI Poker Competition

- AAAI Video Competition

For complete details about any of the AAAI-13 programs, please visit the AAAI-13 website at www.aaai.org/ aaai13.

\section{Artificial Intelligence and the Web Special Track}

This special track invites research papers on AI techniques, systems and concepts involving or applied to the web. Papers should either describe web-related research or clearly explain how the work addresses problems, opportunities or issues underlying the web or web-based systems.

\section{Cognitive Systems Special Track}

In an attempt to return to the original goals of artificial intelligence and cognitive science, this special track invites papers in human-level intelligence, integrated intelligent systems, cognitive architectures, situated embodied cognition, and related areas that aim to explain intelligence in computational terms and reproduce a range of human cognitive abilities in computational artifacts. The track will focus on cognitive capabilities "in the context of complete artificial cognitive systems," hence papers on individual component algorithms will only be accepted if they discuss these algorithms and their functions in conjunction with the rest of the integrated artificial cognitive system.

\section{Computational Sustainability and Artificial Intelligence}

Computational sustainability is a new interdisciplinary field that aims to apply techniques from computer and information science and related disciplines (for example, operations research, applied mathematics, and statistics) to the balancing of environmental, economic, and societal needs, in order to support sustainable development and a sustainable future. This special track invites the submission of research papers on novel concepts, models, algorithms, and systems, in order to address problems in computational sustainability. A broad range of papers ranging from formal analysis to applied research is sought. Examples include papers explaining how the research addresses specific computational problems, opportunities, or issues underlying sustainability challenges and papers describing a sustainability challenge or application that can be tackled using AI methods. Papers proposing general challenges and competitions for computational sustainability are also welcome. 


\section{AAAI Email Addresses}

Please note that AAAI will modify its email addresses in 2013 in an effort to reduce the amount of spam that we are receiving. We will add 13 to all email addresses, as follows:

aaai13 aiide13 aimagazine13 fellows 13 iaai13 aitopics 13 fss 13 icwsm 13 info13 orders 13 membership13 press13 sss13 volunteer13

workshops13

The number will be updated on an annual basis. AAAI can also be reached by filling out the contact form at www.aaai.org/ contact.

\section{Subscribe to the AAAI Announcements List and AI-Alert!}

If you are a member of AAAI and would like to receive periodic announcements and reminders about AAAI programs or other noteworthy AI news, please go to www.aaai.org/lists, choose AAAI-Members in the dropdown, enter your email address, and select "subscribe."

Receive AI in the News automatically each week by subscribing to AI-Alert, a service of AAAI that is read by more than 1,000 of your colleagues each week. Select AI-Alert in the dropdown menu, at www.aaai.org/lists. You can also view the latest news stories that mention $\mathrm{AI}$ at the AITopics home page: www. aaai.org/aitopics (select AI in the News).

If your email address changes, please be sure to follow the instructions for unsubscribing at your old address and subscribing at your new address for each of these lists.

\section{Robotics Special Track}

From the days of Shakey to current automatic cars, Robotics has been a formidable proving ground for artificial intelligence. This special track invites papers that challenge the limits of AI and machine learning algorithms with applications to real-world robotic systems. The track will cover applications of AI to a diverse set of domains, including perception, motion planning, control, human-robot interaction, and decision-making. In 2013, the Robotics track is particularly interested in showcasing research on $3 \mathrm{D}$ perception for navigation, manipulation, and environment understanding; autonomous and human-in-the-loop manipulation; intelligence and perception for human-robot interaction; nonlinear control and decision making; and learning of control, manipulation, and tasks.

\section{Subarea Spotlights Track}

The AAAI Subarea Spotlight Track will feature three invited talk categories, including (1) "What's hot in ..." talks, summarizing the state of the art in a particular area. Talks will explain the main research trends of the last 5-10 years; (2) best-paper talks from a broad cross-section of area conferences, highlighting recent strong research results in each area; and (3) "challenges in ..." talks, summarizing important challenges in a particular area. Talks will outline a vision on where the area should evolve. The line-up of topics will include comprehensive and accessible sessions on the state of the art in a variety of areas, such as constraint programming, games, human-computer interaction, knowledge representation, machine learning, multiagent systems, planning, robotics, SAT, search, the semantic web, and vision.

\section{The Twenty-Fifth IAAI Conference on Artificial Intelligence (IAAI)}

The Twenty-Fifth Annual Conference on Innovative Applications of Artificial Intelligence (IAAI-13) will focus on successful applications of AI technology. The conference will use technical papers, challenge papers, invited talks, and panel discussions to explore issues, methods, and lessons learned in the development and deployment of AI applications, and to promote an interchange of ideas between basic and applied AI. IAAI-12 will consider papers in three tracks: (1) deployed application case studies, (2) challenge problem papers, and (3) emerging applications or methodologies. Submissions should clearly identify which track they are intended for, as the three tracks are judged on different criteria. Authors should consult the IAAI13 Call for Papers for details. For more information, please visit the IAAI-13 website at www.aaai.org/iaai13.

\section{Fourth Symposium on \\ Educational Advances in Artificial Intelligence (EAAI)}

AAAI is pleased to announce the continuation of the AAAI Symposium on Educational Advances in Artificial Intelligence (EAAI), to be held in conjunction with AAAI-13 in Bellevue. The EAAI symposium provides a venue for researchers and educators to discuss pedagogical issues and share resources related to teaching AI and using AI in education across a variety of curricular levels (K-12 through postgraduate training), with an emphasis on undergraduate and graduate teaching and learning. The symposium seeks contributions showing how to more effectively teach AI, as well as how themes from AI may be used to enhance education more broadly (for example, in introductory computing courses or as a means for teaching computational thinking). We encourage the sharing of innovative educational approaches that convey or leverage AI and its many subfields, including robotics, machine learning, natural language processing, computer vision, and so on. EAAI-12 provides several of paths for participation, including full-length papers (6 pages) and presentations for the symposium; extended abstract / poster contributions (2 pages); Model AI Assignments highlighting innovative ready-toadopt materials; a workshop for mentoring new faculty, instructors, and graduate students on teaching; an Educational Video Track within the AAAI-13 Video program; and a Student / Educator Track within the AAAI-13 Robotics Exhibition and 
Workshop. For more information about the symposium, please visit www.aaai.org/eaai13 or write to us at aaai13@aaai.org.

\section{AAAI-13 Workshop Program}

AAAI-13 workshops will be held Sunday and Monday, July 14-15, in Bellevue, Washington. The cochairs of the AAAI-13 Workshop Program are Eric Eaton, Bryn Mawr College (eeaton@cs. brynmawr.edu) and Holger H. Hoos, University of British Columbia (hoos @cs.ubc.ca). The list of accepted workshops will be available in early February 2013, and submissions will be due March 28. Final accepted papers must be received no later than May 9.

\section{AAAI-13 Pre-PhD Student Abstract and Poster Program}

AAAI-13 invites submissions to the pre-PhD student abstract and poster program. The goal of this program is to provide a forum in which students can present and discuss their work during its early stages, meet some of their peers who have related interests, and introduce themselves to more senior members of the field. Additionally, there will be undergraduate-specific activities including mentoring. Submissions are due January 31, 2013. For more information, please write to AAAI at aaai13@aaai.org, or contact the Student Abstract cochairs Rudolph Triebel (University of Oxford, UK, rudi@robots.ox.ac.uk), Kristian Kersting (Fraunhofer IAIS, University of Bonn, Germany, kristian.kersting@iais.fraunhofer.de), and Scott Sanner (NICTA / Australian National University, Australia, scott.sanner@nicta.com.au).

\section{AAAI-13 Doctoral Consortium}

AAAI and ACM/SIGART invite students to apply for the Eighteenth AAAI/SIGART Doctoral Consortium, which will be held as a workshop on July 14-15. The Doctoral Consortium (DC) provides an opportunity for a group of Ph.D. students to discuss and explore their research interests and career objectives with a panel of established researchers in artificial intelligence. The consortium has the following objectives: (1) to provide a setting for mutual feedback on participants' current research and guidance on fu- ture research directions; (2) to develop a supportive community of scholars and a spirit of collaborative research; (3) to support a new generation of researchers by offering advice about academic, research, industrial, and nontraditional career paths; and (4) to contribute to the overall conference goals through interaction with other researchers and participation in conference events. Applications are due February 5, 2013. For more information, please write to AAAI at dc13@ aaai.org, or contact the DC cochairs Peter McBurney (Department of Informatics, King's College London, peter.mcburney@kcl.ac.uk) and Ayanna Howard, Georgia Institute of Technology (ayanna.howard@ece.gatech.edu).

\section{AAAI-13 Conference Volunteer Program}

AAAI is pleased to announce the continuation of its Student Volunteer Programs for 2013. The Student Volunteer Program is an essential part of the conference and student participation is a valuable contribution. Volunteers will support AAAI organizers in Bellevue. In 2013, a limited number of complimentary technical program registrations will be available for students who volunteer during the conference. Preference will be given to participating students for the volunteer positions. Local students or students not requiring travel assistance can apply for the Volunteer Program if openings are available. AAAI membership is required for eligibility. For further information regarding the Student Volunteer Program, please contact AAAI at volunteer13@aaai.org. The deadline for volunteer applications is April 15, 2013.

AAAI also hopes to continue its Student Scholarship program in 2013. Details about this will be posted at the AAAI-13 website as soon as they are available.

\section{Spring Symposium Series}

The 2013 Spring Symposium Series will be held Monday through Wednesday, March 25-27 at Stanford University and will feature eight symposia on the following subjects:
- Analyzing Microtext

- Creativity and (Early) Cognitive Development: A Perspective from Artificial Creativity, Developmental AI and Robotics

- Data Driven Wellness: From Self-Tracking to Behavior Change

ש Designing Intelligent Robots: Reintegrating AI II

- Lifelong Machine Learning

- Shikakeology: Designing Triggers for Behavior Change

- Trust and Autonomous Systems

- Weakly Supervised Learning from Multimedia

Registration information is available at www.aaai.org/spring. Please note that the deadline for registration for invited participants is February 15 and the general registration deadline is March 8. For more information, please write to us at sss13@aaai.org.

\section{Fall Symposium Series}

The 2013 Fall Symposium Series will return to the Westin Arlington Gateway in Arlington, Virginia just outside of Washington, DC, Thursday through Saturday, November 15-17. Proposals for approximately eight symposia are now being accepted. Proposals should be sent no later than February 1, 2013 via email to Symposium Committee Chair Matthew Taylor (Lafayette College) at taylorm@lafayette.edu. For the complete Call for Proposals, please see www.aaai.org/fall.

\section{AAAI Fellows Nominations Solicited}

The 2013 Fellows Selection Committee is currently accepting nominations for AAAI Fellow. The AAAI Fellows program is designed to recognize people who have made significant, sustained contributions to the field of artificial intelligence over at least a tenyear period. All regular members in good standing are encouraged to consider nominating a candidate. At least two references must accompany nominations. The nominator or one of the references must be a AAAI Fellow who is a current member of AAAI. For further information about the Fellows 


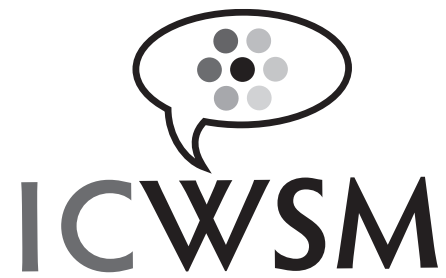

\section{ICWSM-13 Submissions Due February 6, 2013}

The Seventh International AAAI Conference on Weblogs and Social Media (ICWSM-13) will be held at the MIT Media Lab and Microsoft in Cambridge, Massachusetts, USA, July 8-11, 2013. This unique forum brings together researchers from the disciplines of computer science, linguistics, communication, and the social sciences. The broad goal of ICWSM is to increase understanding of social media in all its incarnations. Submissions describing research that blends social science and computational approaches are especially encouraged.

In addition to the usual program of contributed technical talks, posters and invited presentations, the main conference will include a selection of keynote talks from prominent social scientists and technologists. The very successful workshop and tutorial programs will also continue on the first day of the conference, Monday, July 8.

Please note the following important deadlines for ICWSM-13:

$\begin{array}{ll}\text { January } 9 & \text { Workshop Proposal Acceptance } \\ \text { January 15 } & \text { Tutorial Proposal Submission } \\ \text { January 30 } & \text { Paper, Poster, Demo Abstract Submission } \\ \text { February 6 } & \text { Full Paper, Poster, Demo Submission } \\ \text { January 31 } & \text { Tutorial Proposal Acceptance } \\ \text { March 15 } & \text { Paper, Poster, Demo Notifications } \\ \text { March 25 } & \text { Camera Ready Paper Due } \\ \text { July 8-11 } & \text { ICWSM-13 Conference }\end{array}$

For complete submission instructions, deadlines, and other details about the conference, please see www.icwsm.org/2013 or write to icwsm13@aaai.org.

Program or to receive nomination and reference forms, please contact AAAI at 650-328-3123; by fax at $650-321-$ 4457; or by email at fellows13@aaai. org. Nomination materials are also available on the AAAI web site at www.aaai.org/fellows. The deadline for nominations is February 15, 2013.

\section{AAAI \\ Feigenbaum Prize}

The second biennial AAAI Feigenbaum Prize will be awarded in 2013 at the AAAI conference in Bellevue, Washington. The AAAI Feigenbaum
Prize recognizes and encourages outstanding Artificial Intelligence research advances that are made by using experimental methods of computer science. The "laboratories" for the experimental work are real-world domains, and the power of the research results are demonstrated in those domains. The Feigenbaum Prize may be given for a sustained record of highimpact seminal contributions to experimental AI research; or it may be given to reward singular remarkable innovation and achievement in experimental AI research. The prize is $\$ 10,000$ and is provided by the Feigen- baum Nii Foundation and administered by AAAI. For complete details about how to submit nominations for this prize, please see www.aaai.org/ Awards/feigenbaum.php. Nominations are due March 15, 2013.

\section{Special Award Nominations}

AAAI is pleased to announce the continuation of its two special awards in 2013, and is currently seeking nominations for the 2013 AAAI Classic Paper Award, and the AAAI Distinguished Service Award. The 2013 AAAI Classic Paper Award will be given to the author of the most influential paper(s) from the Twelfth National Conference on Artificial Intelligence, held in 1994 in Seattle, Washington. The 2013 AAAI Distinguished Service Award will recognize one individual for extraordinary service to the AI community. Awards will be presented at AAAI-13 in Bellevue, Washington. Complete nomination information, including nomination forms, is available at www.aaai. org/Awards/awards.php. The deadline for nominations is March 15, 2013. For additional inquiries, please contact Carol Hamilton at hamilton@ aaai.org.

\section{AAAI Senior Member Grade of Membership}

AAAI is now taking applications from regular members for the AAAI Senior Member grade of membership. This status is designed to recognize members who have achieved significant accomplishments within the field of Artificial Intelligence. To be eligible for nomination for Senior Member, candidates must be consecutive members of AAAI for at least five years and have been active in the professional arena for at least ten years. Applications should include information that details the candidate's scholarship, leadership, and professional service.

At least two references, one of which must be written by a AAAI Fellow or a current AAAI Senior Member must accompany the senior member application. References should be submitted by colleagues who know the candidate, and are familiar with their 
work and accomplishments. Each year a maximum of 25 members will be elected to the Senior status.

All applications and references must conform to the requirements listed on the form, and must be received by 11:59 PM PST, March 15, 2013. For complete details and an application form, please see www.aaai.org/Awards /senior.php, or contact Carol Hamilton at seniormember13@aaai.org.

\section{AAAI Job Bank}

Check out the latest AI job postings at www.aaai.org/jobs. Postings may also be submitted at the same site.

\section{Visit AAAI on Facebook and LinkedIn}

AAAI is on Facebook and LinkedIn! We invite all interested individuals to check out the Facebook site by searching for AAAI. If you are a current member of AAAI, you can also join us on LinkedIn. We welcome your feedback at info13@aaai.org.

\section{AAAI Gifts Program}

It is the generosity and loyalty of our members that enable us to continue to provide the best possible service to the AI community and promote and further the science of artificial intelligence by sustaining the many and varied programs that AAAI provides. AAAI invites all members and other interested parties to consider a gift to help support the open access initiative, as well as the dozens of other programs that AAAI currently sponsors. For more information about the Gift Program, please see www.aaai.org/donate or write to us at donate13@aaai. org.

\section{AAAI Executive Council Meeting Minutes}

The AAAI Executive Council met July 23, 2012, in Toronto, Canada.

Attending: Henry Kautz, Manuela Veloso, Eric Horvitz, Tom Dietterich, Ted Senator, Tony Cohn, Dieter Fox, Maria Fox, Eduard Hovy, Adele Howe,

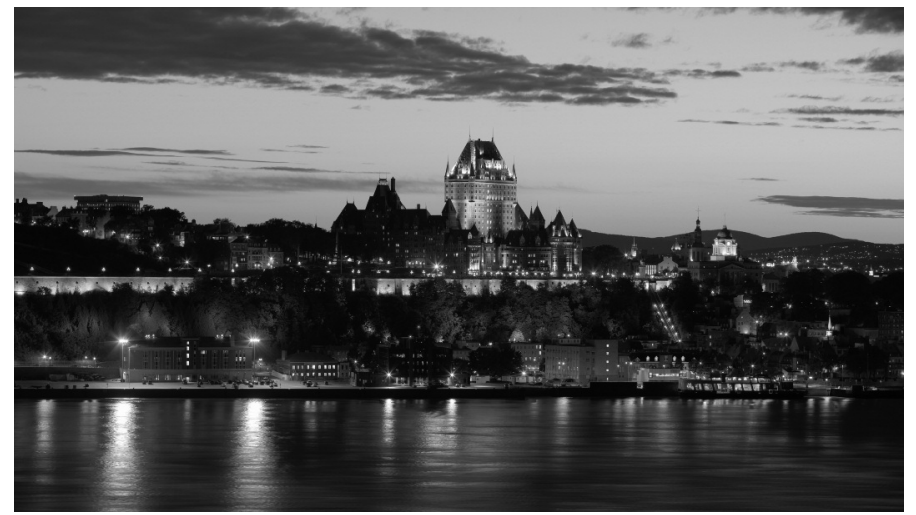

\section{AAAI to Colocate with Cognitive Science Society in 2014 !}

AAAI is pleased to announce that it will colocate with the 2014 Cognitive Science Society Conference in picturesque Québec City, Québec, July 27-31, 2014. The conference will be held at the beautiful Centre des congrès de Québec, and attendees can stay at the adjacent Hilton Québec. More details will be available at the AAAI website soon!

Subbarao Kambhampati, Kate Larson, David Leake, Henry Lieberman, Mark Maybury, Jonathan Schaeffer, Toby Walsh, Makoto Yokoo, Shlomo Zilberstein, Carol Hamilton, Mike Hamilton, Bruce Buchanan, Reid Smith.

Not attending: Carla Brodley, Carla Gomes, Michael Wooldridge, Julia Hirschberg, Alan Schultz.

Henry Kautz called the meeting to order at 9:10 AM, and thanked the retiring councilors (Carla Brodley, Subbarao Kambhampati, Mark Maybury, and Alan Schultz, ex-officio) and Past President Eric Horvitz for their service. He also welcomed the new councilors (Carla Gomes, Julia Hirschberg, Eduard Hovy, and Henry Lieberman) and incoming President-Elect Tom Dietterich.

The minutes of the April 2012 meeting were approved.

Ted Senator reviewed the general duties and responsibilities of an Executive Council member, both in general as members of a nonprofit board and specific expectations of AAAI Executive Councilors and officers.

Attending members introduced themselves.

\section{Standing Committee Reports}

Finance: Ted reviewed the investments of AAAI and the current budget, stressing that the job of the Executive Council is to set priorities for budgetary decisions, but not manage the investments of the association. The council discussed the possibility of converting to an October 1 fiscal year end.

Awards/Fellows/Nominating: Eric Horvitz reviewed the awards and other honors that will be recognized at AAAI this year. There was some discussion about how to better publicize the senior member program and to determine the motivation of why members might want to apply for this honor. The AAAI program is modeled after the ACM program, and there is no prerequisite of being a senior member in order to be a fellow.

Conference Outreach: Kate Larson noted the current list of affiliated and cooperating conferences. There was discussion about how to make this program more appealing to area conferences with increased notifications to the 
AAAI membership or sponsoring a paper at the conference. At the same time, the committee will look at creative ways to draw new members in from these conferences, as requiring a discount on conference fees is not always feasible for smaller events.

International: Maria Fox reviewed the activities of the International committee, which have been concentrated on the fledgling Worldwide AI column in AI Magazine, which was launched in the spring of 2012. Several articles have been submitted, but the committee is finding it challenging. The committee has also found that some articles, especially those from countries with extensive AI research, do not describe a countrywide survey of research, so a mechanism for these types of articles will be explored. Henry Kautz suggested that another useful column might be one describing international research funding opportunities. Another suggestion for the international committee to explore was the idea of tapping into international summer schools, and offering to provide AI speakers. Teaming up with current conference affiliates would be one solution.

Symposium: Kate Larson noted that the committee has been working hard to increase the number of good symposia, particularly at the spring meeting, and has been successful for 2013. She asked the Council members to please send suggestions for symposia throughout the year so that the committee can follow up on them.

Publications: David Leake reported that the fall issue of the AI Magazine will be on Multiagent Systems, and the winter issue will be on IAAI. The Publications Committee is studying options for alternative delivery mechanisms, in addition to print, for the magazine and other publications. Tony Cohn reported that the 2012 AAAI proceedings was 500 pages longer than any previous edition, and the AAAI Press is seeking new projects to publish as ebooks.

Membership: Carol Hamilton reported that membership numbers have hovered around 3,600 for several years, and that several programs have been initiated to help grow membership. These include the Stanford AI Online course complimentary student memberships, platinum conference registrations, the new AAAI Chapter program, and the AAAI Senior Member program, among others. The Council set membership attraction and retention as a priority, and discussed possible approaches in relation to most topics considered during the meeting.

Conference: Dieter Fox reported that AAAI-12 had the largest number of submissions in the history of the conference with 1129 overall. The Council discussed the special tracks and whether they should be continued indefinitely if successful, or rolled into the main technical program. They also discussed the importance of naming tracks to minimize confusion among submitters. The benefit of tracks is that they address the variability in reviewing for specific areas, and also provides higher visibility for emerging areas.

The Council also discussed the Doctoral Consortium, and ways to increase the number of accepted students. The conference committee will follow up with the organizers to see how the structure and finances could be modified to accommodate more student participants. The Poker Competition was organized very differently from previous years with substantial outside funding, and the Council would like to have more information in order to determine how to proceed for the future.

Fox also reviewed other AAAI conferences, including AIIDE and ICWSM. ICWSM has been growing steadily over the past few years. Eric Horvitz gave a brief update on AAAI's newest conference, HCOMP, noting that he has agreed to serve as one of the program cochairs. It is hoped that the first conference will be collocated with AAAI-13 in Bellevue.

For AAAI-13, the Council discussed the possibility of making the banquet included in the registration fee, or available at a greatly reduced fee. One method to offset this expense might be to offer paid tutorials that would be taught by world-class AI researchers in specific areas. Manuela Veloso suggested that a map be post- ed at AAAI-13, noting where attendees are from throughout the world.

In other conference committee news, Fox noted that the committee decided against releasing reviewing data under any circumstances. All future requesters would have to describe the process they plan to use to anonymize data before the request could be considered. The Council also congratulated the committee on the revised process for the selection of the program chairs for the AAAI conference, and suggested that they also ask for suggestions from past conference chairs, fellows, and past councilors in the future. The conference committee will finalize the list of potential candidates, and the Council will vote for the final selection.

Break: AAAI Annual Business Meeting. The installation of the PresidentElect Tom Dietterich and newly elected councilors Carla Gomes, Julia Hirschberg, Eduard Hovy, and Henry Lieberman was completed. Retiring Past President Eric Horvitz and councilors Carla Brodley, Subbarao Kambhampati, Mark Maybury, and Alan Schultz, ex-officio were thanked for their years of service.

\section{Ongoing Business}

AAAI-15: Representatives from Anchorage, Alaska gave a presentation on available facilities and incentives for AAAI-15 in that city. The Council will make a final decision on AAAI-15 in the late fall of 2012 .

AI Topics: Bruce Buchanan reported that the AI Topics site has been dramatically expanded and improved with the help of a summer intern, funded through an NSF grant. Buchanan noted that support for a year-round student intern would be most welcome, and would help the site develop on a steadier basis. The Editorial Board has been less active than hoped, and he and Reid Smith will continue to try to develop this resource. The Council thanked $\mathrm{Bu}$ chanan and Smith for their significant efforts on AI Topics, which is now a tremendously valuable resource for teachers at all levels, students, and the general public.

AAAI Chapters: Manuela Veloso re- 


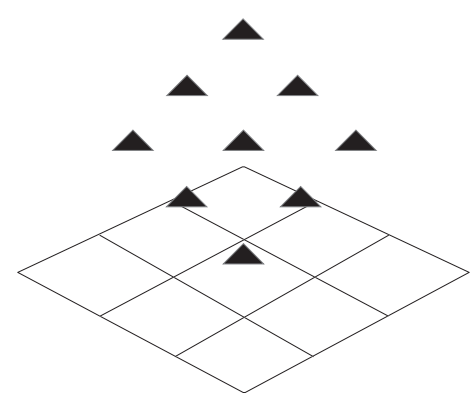

\title{
Registration Is Now Open for the AAAI Spring Symposium Series
}

\author{
Analyzing Microtext \\ Creativity and (Early) Cognitive Development: \\ A Perspective from Artificial Creativity, Developmental AI and Robotics \\ Data Driven Wellness: From Self-Tracking to Behavior Change \\ Designing Intelligent Robots: Reintegrating AI \\ Lifelong Machine Learning \\ Shikakeology: Designing Triggers for Behavior Change \\ Trust and Autonomous Systems \\ Weakly Supervised Learning from Multimedia \\ www.aaai.org/Symposia/Spring/sss13.php
}

viewed the status of the new AAAI Chapter program, noting that the Beijing chapter was launched in October 2011. Plans to establish chapters in other areas are well underway, and a final document describing the program will be posted on the AAAI website. She encouraged council members and other researchers who are traveling to China to contact the Chapter organizers and perhaps arrange to speak to local members. The goal of the chapter program is twofold: to increase international membership, but more importantly to spread the word about AI throughout the world.

AAAI Future: Henry Kautz shared some general thoughts about the current state of AAAI and his ideas for changing the direction of the society. He noted that while membership has declined during the last ten years, submissions to the conference have increased significantly. The AAAI reviewer pool has increased much faster than the submissions, however, and the percentage of AAAI members among the program committee is quite low. Kautz suggested that the program committee be revamped to include more active AAAI members, the program committee meeting be reestablished, and the conference submission process be run more like a journal with rolling submissions, non-anonymous submissions, and possibly two conferences during the year. (Specific conference issues, such as anonymous reviewing, number of reviews, and submission software will be studied by the conference committee during the next three months, and the committee will develop a plan to be implemented for 2014.)

Kautz also noted that in order to grow membership, AAAI needs to expand its focus to include more reasons to become a member of AAAI, and would like feedback from the larger AI community to determine priorities. Tom Dietterich would like to explore the possibility of weekly or monthly electronic publication in AI, similar to Science. Manuela Veloso is working with IJCAI and other conferences to implement mechanisms for their conference attendees to opt for a discounted AAAI introductory membership. Carol Hamilton will al- so offer conference nonmembers an introductory complimentary membership in AAAI. The Council set a high priority to increase membership during the next two years via many of the methods discussed throughout the day, as well as others to be determined.

Manuela Veloso will establish three working groups to study the issues raised by Kautz, and Skype meetings will be scheduled for each working group. An Executive Council meeting will be scheduled to report back on discussions. Veloso will be circulating a set of topics for council members to sign up for, and a survey of the membership will be planned.

Carol Hamilton will circulate the list of committees and current committee members so that new council members can send their preferences regarding committee assignment. Rao Kambhampati agreed to serve as the new Conference Committee chair, as Dieter Fox has completed his term on the Council.

The meeting was adjourned at 4:30 PM. 


\begin{tabular}{|c|c|c|}
\hline \multicolumn{3}{|l|}{ ASSETS } \\
\hline \multicolumn{3}{|l|}{ Current Assets } \\
\hline Cash and cash equivalents & $\$$ & 155,716 \\
\hline Investments & & $6,843,823$ \\
\hline Accounts receivable & & 34,019 \\
\hline Inventory & & 99,252 \\
\hline Prepaid expenses & & 16,414 \\
\hline Deposits & & 5,535 \\
\hline Total Current Assets & & $7,154,759$ \\
\hline \multicolumn{3}{|l|}{ Non-Current Assets } \\
\hline Equipment, net of accumulated depreciation & & 17,453 \\
\hline Total Assets & $\$$ & $7,172,212$ \\
\hline \multicolumn{3}{|l|}{ LIAB ILITIES } \\
\hline Accounts payable & $\$$ & 43,612 \\
\hline Accrued vacation & & 46,470 \\
\hline Funds held in trust for other organizations & & 254,188 \\
\hline Unearned membership fees & & 274,804 \\
\hline Other deferred revenues & & 13,347 \\
\hline Total Liabilities & & 632,421 \\
\hline \multicolumn{3}{|l|}{ NET ASSETS } \\
\hline Unrestricted & & $6,539,791$ \\
\hline Total Liabilities and Net Assets & $\$$ & $7,172,212$ \\
\hline
\end{tabular}

Statement of Financial Position, December 31, 2011.

\section{Association for the Advancement of Artificial Intelligence (A California Nonprofit Corporation) Financial Statements December 31, 2011 with Independent Auditor's Report}

\section{Independent Auditor's Report}

The Board of Directors

Association for the Advancement of Artificial Intelligence

Palo Alto, California

We have audited the accompanying statement of financial position of the Association for the Advancement of Artificial Intelligence (a California nonprofit corporation) as of December 31,2011 , and the related statements of activities, cash flows and functional expenses for the year then ended. These financial statements are the responsibility of the Association for the Advancement of Artificial Intelli- gence's management. Our responsibility is to express an opinion on these financial statements based on our audit.

We conducted our audit in accordance with auditing standards generally accepted in the United States of America. Those standards require that we plan and perform the audit to obtain reasonable assurance about whether the financial statements are free of material misstatement. An audit includes examining, on a test basis, evidence supporting the amounts and disclosures in the financial statements. An audit also includes assessing the accounting principles used and significant estimates made by management, as well as evaluating the overall financial statement presentation. We be- lieve that our audit provides a reasonable basis for our opinion.

In our opinion, the financial statements referred to above present fairly, in all material respects, the financial position of Association for the Advancement of Artificial Intelligence as of December 31, 2011, and the changes in net assets and its cash flows for the year then ended, in conformity with accounting principles generally accepted in the United States of America.

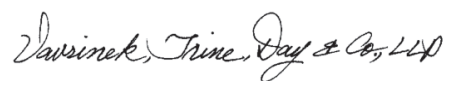

Vavrinek, Trine, Day \& Co., LLP

Palo Alto, California

May 29, 2012 


\section{Revenues}

Program revenues

Membership fees

Investment income, net of investment expenses

Total Support and Revenues

\section{Expenses}

Program services

Membership services

Supporting services

Total program and supporting services

CHANGE IN NET ASSETS

NET ASSETS, BEGINNING OF YEAR

NET ASSETS, END OF YEAR

\begin{tabular}{rr}
\hline Unrestricted \\
\hline & \\
\hline$\$ \quad 1,117,390$ \\
396,324 \\
$(25,600)$ \\
\hline $1,488,114$ \\
\hline & \\
\hline & $1,017,555$ \\
\hline & 312,396 \\
4 & 416,576 \\
\hline & $1,746,527$ \\
\hline & \\
& $(258,413)$ \\
\hline & \\
\hline & $6,798,204$ \\
\hline$\$$ & $6,539,791$ \\
\hline
\end{tabular}

Statement of Activities for the Year Ended December 31, 2011.

\section{CASH FLOWS FROM OPERATING ACTIVITIES}

Change in net assets

$\$(258,413)$

Adjustments to reconcile change in net assets to net cash provided by operations

Depreciation

Unrealized and realized gain and loss on investment

Increase in accounts receivable

$(19,439)$

Decrease in inventory

12,307

Increase in prepaid expenses

Decrease in deposit

1,981

Decrease in accounts payable

$(10,117)$

Increase in accrued vacation

7,283

Increase in funds held in trust

29,869

Decrease in unearned membership fees

$(14,598)$

Decrease in other deferred revenues

$(11,100)$

Net Cash Used by Operating Activities

$(51,053)$

\section{CASH FLOWS FROM INVESTING ACTIVITIES}

Purchase of furnishings and equipment

Sale of investments

Purchase of investments, net of purchases fees

Net Cash Provided by Investing Activities

NET DECREASE IN CASH AND CASH EQUIVALENTS

$(40,609)$

CASH AND CASH EQUIVALENTS, Beginning of Year

CASH AND CASH EQUIVALENTS, End of Year 


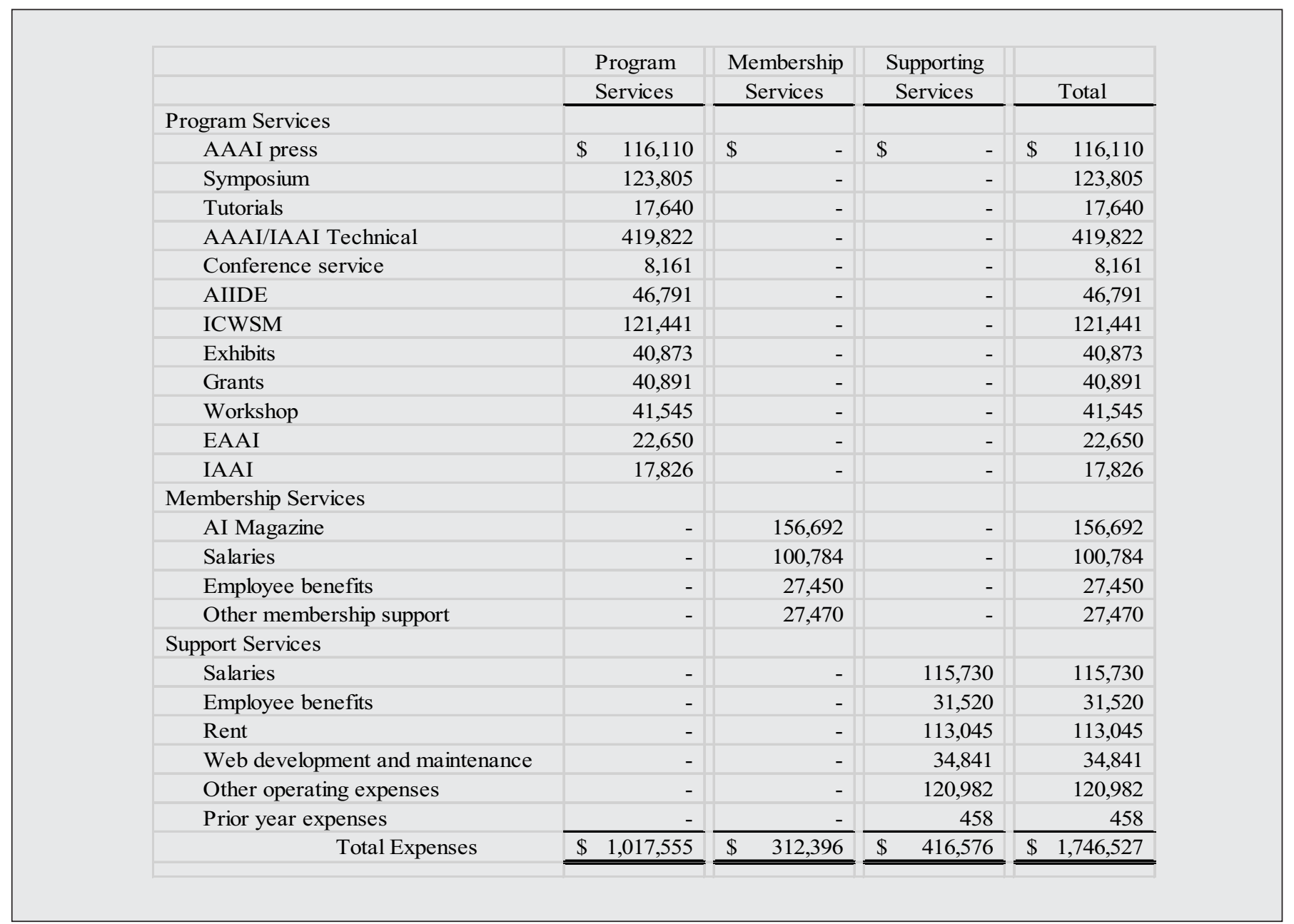

Statement of Functional Expenses for the Year Ended December 31, 2011.

\section{Notes to Financial Statements, December 31, 2011}

\section{Note \#1. Nature of Organiza- tion and Significant Account- ing Policies}

\section{Organization}

The Association for the Advancement of Artificial Intelligence (the "Association") was incorporated in the State of California in 1979 as a nonprofit scientific society to encourage the basic knowledge of what constitutes intelligent thought and behavior and how it can be exhibited in computers. This is accomplished primarily by the AI Magazine, the publications of AAAI Press, the AAAI Conference on Artificial Intelligence (AAAI), the Conference on Innovative Applications of Artificial Intelligence (IAAI), the Conference on Artificial Intelligence and Interactive Digital Entertainment (AIIDE), the International AAAI Conference on Weblogs and Social Media (ICWSM), the AAAI Spring and Fall Symposium Series, the
AAAI Workshop program, AAAI student programs, and a series of AI-related annual competitions and exhibitions, including those on robotics, poker, general game playing, and AI videos. In addition, AAAI awards grants and scholarships, and has a program in place to honor distinguished members of the artificial intelligence community. Finally, AAAI's World Wide Web Site serves as a central resource for individuals involved in AI research.

\section{Financial Statement Presentation}

The Association presents its financial statements in accordance with Statement of Financial Accounting Standards (SFAS) No. 117, "Financial Statements of Not-for-Profit Organizations." Under SFAS No. 117, the Association is required to report information regarding its financial position and activities according to three classes of net assets: unrestricted net assets, temporarily re- stricted net assets, and permanently restricted net assets. The Association only has unrestricted net assets. Contributions received with donor-imposed restrictions that are met in the same year in which the contributions are received are classified as unrestricted contributions. In addition, the Association is required to present a statement of cash flows. As permitted by the statement, the Association does not use fund accounting. Revenues and expenses are recorded when incurred in accordance with the accrual basis of accounting.

\section{Investments}

The Association presents its investments in accordance with SFAS No. 124, "Accounting for Certain Investments Held by Not-forProfit Organizations." Under SFAS No. 124, investments in marketable securities with readily determinable fair values and all investments in debt securities are reported at their fair values in the statement of finan- 
cial position. Unrealized gains and losses are included in the change in net assets. All investment income and gains are reported as increases in unrestricted net assets if the restrictions are met (either by passage of time or by use) in the reporting period in which the income and gains are recognized.

\section{Inventories}

All inventories are valued at cost, using the weighted average method. The Association's inventories consist of AAAI Press Books and CD ROMs.

\section{Equipment}

Equipment is stated at cost, or if donated, at estimated fair value on the date of donation. Routine maintenance and repairs are charged to expense as incurred. Depreciation is computed on the straight line method based on the assets' estimated useful lives ranging from five to ten years. Depreciation expense for the year ended December 31,2011 , was $\$ 7,178$.

\section{Use of Estimates}

The preparation of financial statements in conformity with accounting principles generally accepted in the United States of America requires management to make estimates and assumptions that affect the reported amounts of assets and liabilities, and disclosure of contingent assets and liabilities, at the date of the financial statements and the reported amounts of revenues and expenses during the reporting period. Actual results could differ from those estimates. There is no significant estimate during the reporting period.

Cash and Cash Equivalents

Cash and cash equivalents consist of cash held in checking and money market accounts with maturities of less than 90 days.

\section{Income Taxes}

The Association is a nonprofit corporation that is exempt from income taxes under Section 501(c) (3) of the Internal Revenue Code and Section 23701(d) of the California Revenue and Taxation Code. Federal and California taxes were paid during 2011 on earnings from sales of mailing lists and advertising.

\section{Allocation of Functional Expenses}

The costs of providing the various programs and other activities have been summarized on a functional basis in the Statement of Functional Expenses. Accordingly, certain costs have been allocated among the programs benefited.

\section{Note \#2. Investment Securities}

Investments in equity securities with readily determinable fair values and all debt securities are carried at fair value. Fair value is determined using quoted market prices (where available), or if not available, estimated fair values are determined based on quoted market prices of financial instruments with similar characteristics. All other investments are carried at the lower of cost or market. Recognized gains and losses on investments are reflected in the statement of activities. Dividends and interest income are recorded during the period earned.

Investment activity for the years ended December 31, 2011 is shown in the Note \#2 table on page 14 .

\section{Note \#3. Market Value of Financial Assets and Liabilities}

The Association determines the fair market values of certain financial instruments based on the fair value hierarchy established in Statement of Financial Accounting Standards, Fair Value Measurements, which requires an entity to maximize the use of observable inputs and minimize the use of unobservable inputs when measuring fair value. The standard describes three levels of inputs that may be used to measure fair value.

The following provides a summary of the hierarchical levels used to measure fair value:

\section{Level 1}

Quoted prices in active markets for identical assets or liabilities that the reporting entity has the ability to access at the measurement date. Level 1 asset and liabilities may include debt and equity securities that are traded in an active exchange market and that are highly liquid and are actively traded in over-the-counter markets.

\section{Level 2}

Observable inputs other than Level 1 prices such as quoted prices for similar assets or liabilities; quoted prices in markets that are not active; or other inputs that are observable or can be corroborated by observable market data for substantially the full term of the assets or liabilities. Level 2 assets and liabilities may include debt securities with quoted prices that are traded less frequently than exchange-traded instruments and other instruments whose value is determined using a pricing model with inputs that are observable in the market or can be derived principally from or corroborated by observable market data. This category generally includes U.S. Government and agency mortgage-backed debt securities, corporate debt securities, derivative contracts, residential mortgage, and loans held-for-sale.

Level 3

Unobservable inputs that are supported by little or no market activity and that are sig- nificant to the fair value of the assets or liabilities. Level 3 assets and liabilities include financial instruments whose value is determined using pricing models, discounted cash flow methodologies, or similar techniques, as well as instruments for which the determination of fair value requires significant management judgment or estimation. This category generally includes certain private equity investments, retained residual interests in securitizations, residential MSRs, asset-backed securities (ABS), highly structured or long-term derivative contracts and certain collateralized debt obligations (CDO) where independent pricing information was not able to be obtained for a significant portion of the underlying assets.

Assets and Liabilities Recorded at Fair Value on a Recurring Basis

The Note \#3 table on page 14 presents the balances of the assets measured at fair value on a recurring basis as of June 30, 2011. The Association did not have any liabilities measured at fair value on a recurring basis as of June 30, 2011.

The Foundation did not have any assets or liabilities recorded at fair value on a nonrecurring basis.

\section{Note \#4. Equipment}

Property and equipment at December 31, 2011, is shown in the Note \#4 table on page 14 .

\section{Note \#5. Memberships}

Annual membership in the Association is \$135 for individuals, \$65 for student members, and $\$ 275$ for academic or corporate libraries. The annual membership fee includes free access to AAAI digital library. The back issue of the AI magazine can be purchased for $\$ 10$ per issue. An additional $\$ 7$ postage fee applies to members outside of the U.S. and Canada. Three year, five year, and lifetime memberships are also available. Revenues from membership fees are earned ratably over the respective membership period. Lifetime membership fees are recognized as income over ten years.

\section{NOTE \#6. Pension Benefits}

The Association sponsors a pension plan under Section 403(b) of the Internal Revenue Code. The plan is a defined contribution plan. The Association contributes to individual accounts five percent of their salaries for regular, full-time employees who have worked a minimum of two years at AAAI. In addition, AAAI matches employees' contributions up to five percent of their salaries for regular, full-time employees who have worked a minimum of two years at AAAI. 
Realized gains on investments

\$ $\quad 22,797$

Unrealized loss on investments

$(227,933)$

Interest and dividends

179,596

Total investment income

$(25,540)$

Investment expenses

(60)

Total investment income, net of expenses

$(25,600)$

Note \#2 Table.

\section{ASSETS}

Common and preferred stocks

U.S. obligation bonds

Corporation bonds

Total
Level 1

\$ $4,580,006$

$1,584,672$

679,145

$\$ \quad 6,843,823$

Note \#3 Table.

\begin{tabular}{|c|c|c|c|c|c|c|c|}
\hline \multirow[b]{3}{*}{ Equipment } & \multicolumn{2}{|c|}{ Beginning } & \multirow{2}{*}{\multicolumn{2}{|c|}{ Additions }} & \multirow{2}{*}{\multicolumn{2}{|c|}{ Deletions }} & \multirow{2}{*}{$\begin{array}{c}\text { End of } \\
\text { Year }\end{array}$} \\
\hline & \multicolumn{2}{|c|}{ of Year } & & & & & \\
\hline & $\$$ & 80,905 & $\$$ & 10,614 & $\$$ & - & $\$ \quad 91,519$ \\
\hline & $\$$ & 14,017 & $\$$ & 3,436 & $\$$ & - & 17,453 \\
\hline
\end{tabular}

Note \#4 Table.

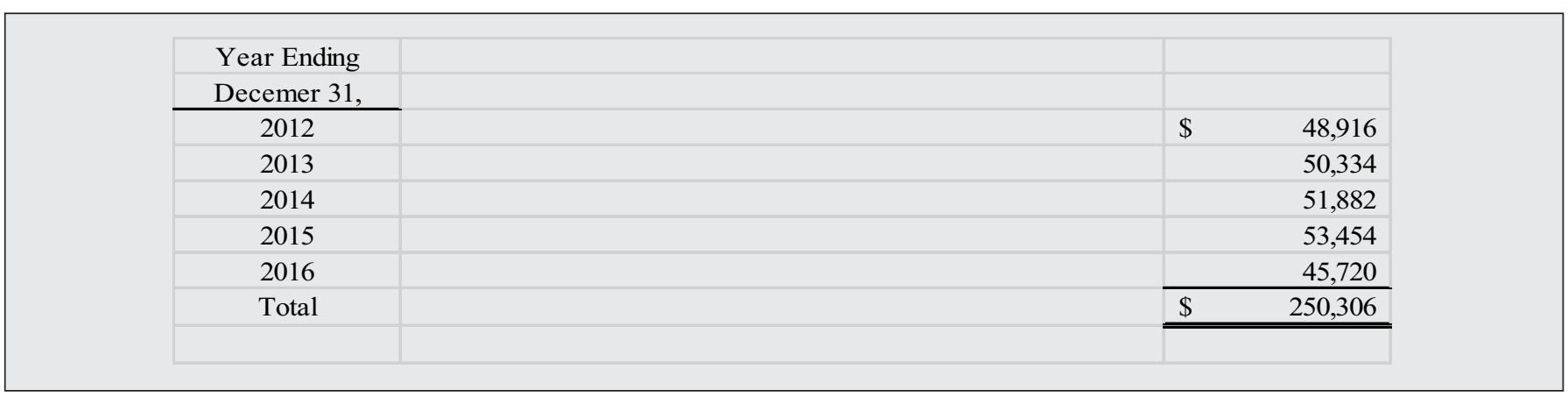

Note \#7 Table.

\section{NOTE \#7. Lease Commitments}

The Association sponsors entered into a lease agreement for its office space expiring on October 31, 2016. The Association is committed to make scheduled annual lease payments shown in table 7 .

\section{NOTE \#8. Related Party Transactions}

A business owned by an individual related to a key employee of the Organization provides printing and/or consulting services to the Organization. During the year ended December 31, 2011, the amount paid for those services was approximately $\$ 228,597$.

\section{NOTE \#9. Subsequent Events}

The Organization's management has evaluated events or transactions that may occur for potential recognition or disclosure in the financial statements from the balance sheet date through May 29, 2011, which is the date the financial statements were available to be issued. Management has de- termined that there were no subsequent events or transactions that would have a material impact on the current year financial statements. 